\title{
Two mutations of dihydropteridine reductase deficiency
}

\author{
A PONZONE, ${ }^{*}$ O GUARDAMAGNA, ${ }^{*}$ S FERRARIS, ${ }^{*}$ G BRACCO,$\dagger$ A NIEDERWIESER, \\ AND R G H COTTON\& \\ ${ }^{*}$ Pediatric Clinic, University of Turin, $†$ Regina Margherita Children’s Hospital, Turin, Italy, $\ddagger$ Department of \\ Pediatrics, University of Zürich, Switzerland, and \$Murdoch Institute, Royal Children's Hospital, Parkville, \\ Australia
}

SUMmaRY Two patients with dihydropteridine reductase (DHPR) deficiency, in one case due to the absence of any enzyme protein (DHPR ${ }^{-}$cross reactive material $\left.(\mathrm{CRM})^{-}\right)$and in the other case due to the production of a mutant type devoid of catalytic activity (DHPR ${ }^{-} \mathrm{CRM}^{+}$) were examined. This latter form of malignant phenylketonuria, whose relative frequency seems to be higher in the Italian population, possibly has a worse prognosis. The earlier onset and the greater severity of clinical symptoms are associated with a more pronounced hydroxylation defect, as shown by higher degree of neonatal hyperphenylalaninaemia, unresponsiveness to an oral tetrahydrobiopterin load, lower concentrations of neurotransmitter metabolites, and reduced tyrosine production after an oral phenylalanine load.

The first observation that concerns the lack of response of phenylketonuric children to dietary treatment is that of Mary Efron in 1965 reported by McKusick. ${ }^{1}$ Dr Efron pointed out that phenylketonuria (PKU) seldom affects people of southern Italian origin, but when it does, it is unresponsive to diet and causes death in the first years of life. The observation may have been the result of some type of tetrahydrobiopterin $\left(\mathrm{BH}_{4}\right)$ deficiency, which was not recognised at that time, as a possible cause of primary hyperphenylalaninaemia. This hypothesis is supported by the recent finding that among people of southern Italian origin the frequency of $\mathrm{BH}_{4}$ deficiency seems higher than in other populations, mainly due to the higher prevalence, and clustering in Sicily, of dihydropteridine reductase (DHPR) deficiency. ${ }^{2}$ As this form of atypical PKU is known to be heterogeneous with respect to the molecular defect ${ }^{3}$ and the response of an oral $\mathrm{BH}_{4}$ load, ${ }^{4}$ two patients deficient in DHPR, originating from the south of Italy and with different clinical presentations, were evaluated in an attempt to determine a correlation with their enzyme state and $\mathrm{BH}_{4}$ responsiveness.

\section{Case reports}

A girl (case 1), born on 20 February 1983, was the second child of second cousin parents originally from Calabria, a region of southern Italy. She had $7 \mathrm{mg} \%$ plasma phenylalanine at 4 days of age on Guthrie mass screening, and had confirmed diagnosis of hyperphenylalaninaemia $(1268 \mu \mathrm{mol} / \mathrm{l})$ at the age of 20 days when a phenylalanine restricted diet was started. Physical and neurological development was judged to be normal up to the age of 7 months, although head circumference seemed to be reduced from the sixth month. Her phenylalanine tolerance, unlike that in PKU, was stable at the high value of about $60 \mathrm{mg} / \mathrm{kg} / \mathrm{day}$. Over the next few months it was evident that she was slow in reaching developmental milestones and there was subsequent regression with progression of the typical neurological picture of $\mathrm{BH}_{4}$ deficiency. An electroencephalogram gave repeatedly normal results, and no episodes of hyperthermia occurred. The diagnosis of DHPR deficiency was made at the age of 10 months and treatment with levodopa, 5-hydroxytryptophan, and carbidopa was added to the phenylalanine restricted diet. After several adjustments, ${ }^{5}$ the clinical response to the treatment was good. The girl is now attending a kindergarten, has no gross motor or speech disabilities, and her intelligence quotient was 95 at the age of 3 years and 9 months.

A boy (case 2), born on 4 April 1983, was the third child of first cousin parents who originated 
from Sicily. A neonatal Guthrie test was not done and he was on a free diet until the age of 10 months when the hyperphenylalaninaemia was ascertained $(1320 \mu \mathrm{mol} / \mathrm{l})$. Difficulty in feeding, extreme truncal hypotonia, and eye deviation had appeared in the first two months of life, and by the fifth month psychomotor deterioration, microcephaly (head circumference below the third centile), repeated daily myoclonic convulsions and hypsarrhythmic activity shown on electroencephalography were present. A phenylalanine restricted diet was started at 10 months, and neurotransmitter treatment was added at 13 months after the diagnosis of DHPR deficiency. Despite the severity of the clinical picture and the delay in beginning treatment, the patient slowly improved. Convulsions stopped within six months with electroencephalography giving normal results. Motor disabilities and behavioural abnormalities diminished and head circumference increased (it is now over the 10th centile). At 2 years 6 months of age the patient started walking and speaking some simple words; his intelligence quotient, however, was only 45 at the age of 3 years and 5 months.

\section{Methods and results}

The activity of DHPR was measured by assay of dried blood spots $^{6}$ and on cultured fibroblasts. ${ }^{7}$ Both methods showed no activity in the patient's cells. All four parents exhibited intermediate values (table 1).

Immunoprecipitation of DHPR was carried out after labelling of fibroblasts with ${ }^{35} \mathrm{~S}$ methionine. ${ }^{89}$ Immunoprecipitates were then separated by sodium dodecyl sulphate polyacrylamide electrophoresis according to Laemmli ${ }^{10}$ and detected by fluorography. The method was sensitive enough to detect $5 \%$ of normal enzyme concentrations. Cross reactive material (CRM) was present at near normal concentrations in the boy (case 2) and was absent in the girl (case 1); this has already been reported by us. ${ }^{9}$

Serum folate measurements were performed by means of a commercial radioassay kit (Ciba Corning MAGIC Vitamin $\mathrm{B}_{12} /$ Folate NB) at diagnosis and after 10 days of oral administration of folinic acid at $15 \mathrm{mg} /$ day (table 1). Only the girl was found deficient in folate, but both patients failed to show any metabolic or clinical improvement with this treatment.

An oral $\mathrm{BH}_{4}$ loading test was given to both patients. ${ }^{11}$ As the boy showed no reduction in plasma phenylalanine concentrations he was given $2 \mathrm{mg} / \mathrm{kg} \mathrm{BH} \mathrm{BH}_{4}$ intravenously, to which he responded partially (table 2 ).

Urine and cerebrospinal fluid (CSF) pterins, CSF neurotransmitter metabolites, homovanillic acid (HVA) and 5-hydroxyndole acetic acid (5-HIAA) were measured by high performance liquid chromatography with electrochemical detection at high and low plasma concentrations of phenylalanine (table 3). ${ }^{12}$ The urinary and CSF pterin patterns were similar in the two patients, in both of whom the pterin pattern reverted towards normal under dietary treatment. At diagnosis the boy showed

Table 2 Plasma phenylalanine response to loading with tetrahydrobiopterin $\left(\mathrm{BH}_{4}\right)$ in the two patients

\begin{tabular}{|c|c|c|c|c|}
\hline \multirow{2}{*}{$\begin{array}{l}\text { Case } \mathrm{No} \\
\text { and route } \\
\text { of administration } \\
\text { of } \mathrm{BH}_{4}\end{array}$} & \multirow{2}{*}{$\begin{array}{l}\text { Dose of } \\
\mathrm{BH}_{4} \\
(\mathrm{mg} / \mathrm{kg})\end{array}$} & \multicolumn{3}{|c|}{$\begin{array}{l}\text { Plasma phenylalanine } \\
\text { concentration ( } \mu \text { mol/l) }\end{array}$} \\
\hline & & 0 & 4 hours & 8 hours \\
\hline Case 1: oral & $7 \cdot 5$ & 478 & 208 & 110 \\
\hline Case 2: oral & $7 \cdot 5$ & 1386 & 1380 & 1344 \\
\hline intravenous & $2 \cdot 0$ & 960 & 934 & 764 \\
\hline
\end{tabular}

Table 1 Dihydropteridine reductase (DHPR) activity in dried blood spots and in cultured fibroblasts of the two families, and serum folate values in the patients before and after folinic acid treatment

\begin{tabular}{|c|c|c|c|c|}
\hline & \multicolumn{2}{|l|}{ DHPR activity } & \multicolumn{2}{|c|}{ Serum folate $(\mathrm{ng} / \mathrm{ml})$} \\
\hline & Erythrocytes & Fibroblasts & Day 0 & Day 10 \\
\hline $\begin{array}{l}\text { Case } 1 \\
\text { Father } \\
\text { Mother }\end{array}$ & $\begin{array}{l}\text { None detected } \\
1 \cdot 14 \\
1 \cdot 82\end{array}$ & $\begin{array}{l}\text { None detected } \ddagger \\
\text { Not determined } \\
\text { Not determined }\end{array}$ & $2 \cdot 7$ & 20 \\
\hline $\begin{array}{l}\text { Case } 2 \\
\text { Father } \\
\text { Mother }\end{array}$ & $\begin{array}{l}\text { None detected } \\
1 \cdot 37 \\
0.92\end{array}$ & $\begin{array}{l}\text { None detected } \\
\text { Not determined } \\
\text { Not determined }\end{array}$ & 20 & 43 \\
\hline Controls & $\begin{array}{l}3 \cdot 34(0 \cdot 88)^{*} \\
(n=20)\end{array}$ & $\begin{array}{l}49 \cdot 6(2 \cdot 8) \dagger \\
(n=11)\end{array}$ & $3-17$ & \\
\hline
\end{tabular}

*Value is mean (SD) (nmol cytochrome $\mathrm{C}$ reduced/minute $/ 5 \mathrm{~mm}$ diameter, filter paper disc).

†Value is mean (SD) (nmol NADH oxidised/minute/mg protein).

$\ddagger 1 \%$ of normal activity could be confidently assayed. 
Table 3 Pattern of pterins in urine and cerebrospinal fluid; concentrations of homovanillic acid (HVA) and 5-hydroxyndole acetic acid (5-HIAA) recorded in the two patients in basal conditions and during phenylalanine restricted diet with substitutive neurotransmitter treatment

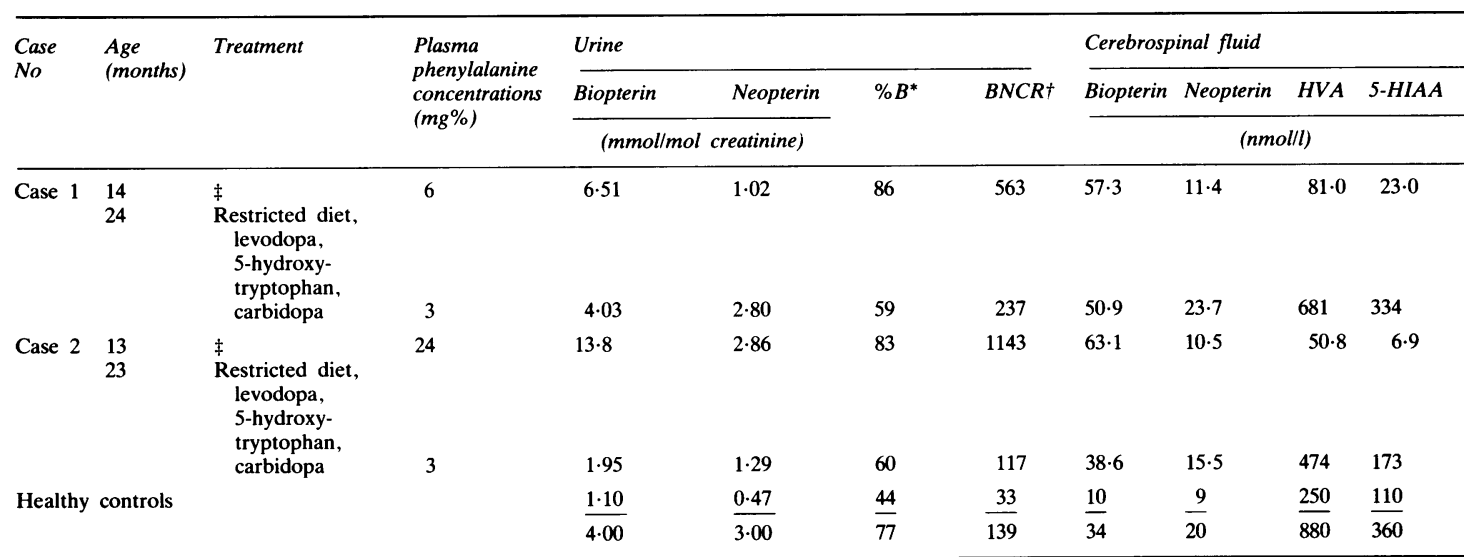

$* \% \mathrm{~B}=100 \times$ biopterin/biopterin+neopterin.

+ BNCR (biopterin neopterin creatinine ratio) $=$ biopterin/biopterin + neopterin $\cdot$ biopterin $/$ creatinine $\cdot 10^{5}$

$\ddagger$ In both cases the treatment was discontinued for more than a week: in case 1 because the drugs were not available and because of the high phenylalanine tolerance; in case 2 the parents were initially not fully convinced of the benefit of the treatment.

lower HVA and 5-HIAA concentrations in the CSF than the girl, but he also had higher phenylalanine concentrations. Correction was achieved in both patients with similar doses of hydroxylated neurotransmitter precursors.

An oral load of phenylalanine $(0.6 \mathrm{mmol} / \mathrm{kg})$ was given, ${ }^{13}$ and amino acids were measured chromatographically with the Kontron Chromakon 500 automatic analyser. The impairment of hydroxylating activity was possibly more pronounced in the boy, as indicated by a somewhat slower fall in plasma concentrations of phenylalanine and lesser rise in tyrosine (figure).

\section{Discussion}

Clinical variation in patients with inborn errors of metabolism is common due to quantitative as well as qualitative differences in underlying mutations and additional factors. Three different enzyme defects

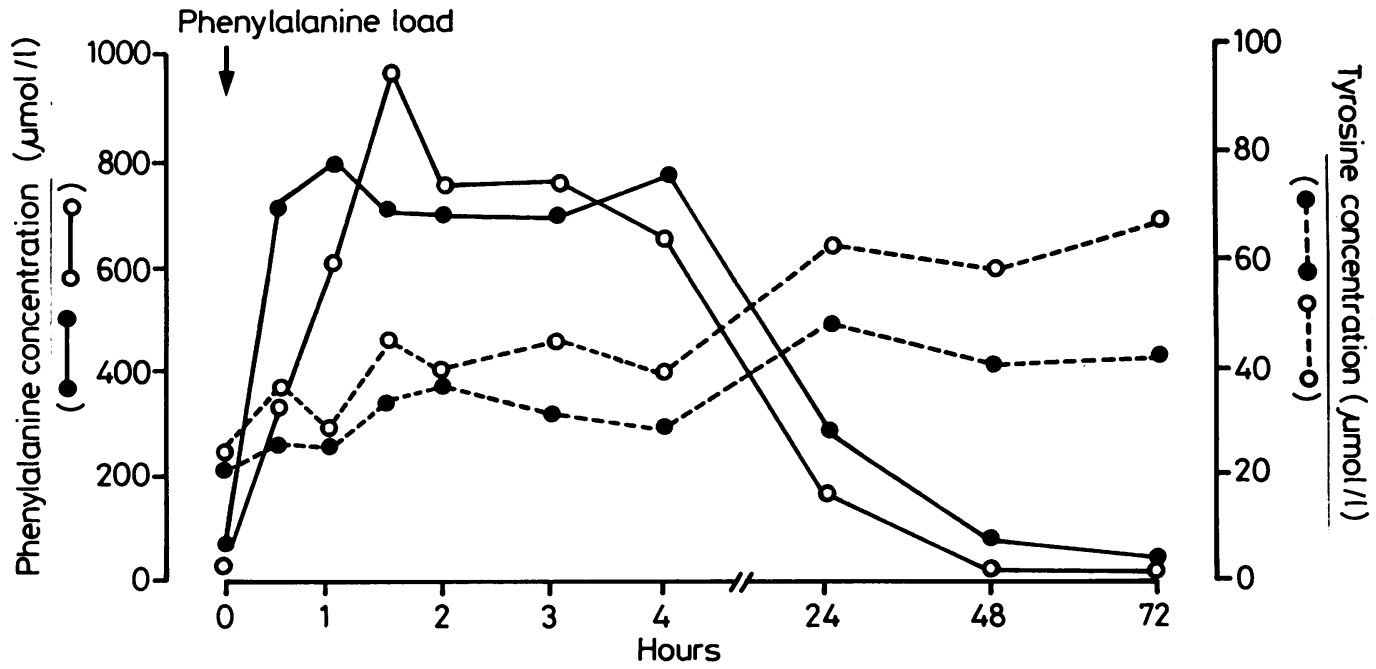

Figure Plasma phenylalanine (-) and tyrosine (- - ) responses to an oral phenylalanine load in the girl $\left(\mathrm{O}^{-}\right.$) who did respond to the load with tetrahydrobiopterin $\left(\mathrm{BH}_{4}\right)$ and the boy $(\mathrm{O})$ who did not respond. 
cause $\mathrm{BH}_{4}$ deficiency, guanosine triphosphate cyclohydrolase I (GTP-CH I) and 6-pyruvoyl tetrahydropterin synthase (PTPS) deficiency causing impaired synthesis and DHPR deficiency causing impaired recycling of the cofactor. ${ }^{4}$ Further heterogeneity has been described within these defects. ${ }^{14}$ The use of a $\mathrm{BH}_{4}$ oral load as a diagnostic tool has shown that a minority of patients deficient in DHPR fail to lower their plasma phenylalanine after loading, ${ }^{4}$ and in addition it has been shown that some patients have no mutant protein $\left(\mathrm{DHPR}^{-} \mathrm{CRM}^{-}\right)$in their cells, whereas others have $\left(\mathrm{DHPR}^{-} \mathrm{CRM}^{+}\right){ }^{3}{ }^{15}$ It has been reported that $\mathrm{CRM}^{-}$cases are $\mathrm{BH}_{4}$ responders and $\mathrm{CRM}^{+}$are non-responders and that the latter have a worse prognosis. ${ }^{9}$

The present study strengthens the hypothesis that the presence of the mutant DHPR is worse clinically: shown by the earlier onset of symptoms and the relatively poor clinical response to neurotransmitter treatment in the patient with $\mathrm{CRM}^{+}$, although the delay in starting a phenylalanine restricted diet could also have contributed.

Contrary to the opinion that the unresponsiveness to exogenous $\mathrm{BH}_{4}$ could be due to the total deficiency of DHPR catalytic activity, ${ }^{16}$ this was present in both our patients and only the child who was $\mathrm{CRM}^{+}$gave a negative response after oral loading. Unresponsiveness to exogenous $\mathrm{BH}_{4}$ could be due to the binding of cofactor to the mutant enzyme, making $\mathrm{BH}_{4}$ unavailable for hydroxylation. If so, a decrease of plasma phenylalanine might be achieved by loading these patients with doses of $\mathrm{BH}_{4}$ large enough to exceed the $\mathrm{CRM}^{+}$binding capacity; the $\mathrm{CRM}^{+}$patient described here did respond to intravenous $\mathrm{BH}_{4}$, and together with another non-responding patient also responded to higher oral doses. ${ }^{17}$ Alternative hypotheses might be the production of a reactive pterin, which inactivates hydroxylases, or the inhibition of the hydroxylases by the mutant enzyme. In any of these cases, the endogenous biosynthetic $\mathrm{BH}_{4}$ would be less available in $\mathrm{CRM}^{+}$patients, leading to a worse outcome. The $\mathrm{CRM}^{+}$patient described here may have had a more pronounced hydroxylation defect than the child who was $\mathrm{CRM}^{-}$in view of the lower basal concentrations of HVA and 5-HIAA, and the reduced tyrosine production after oral phenylalanine load. Furthermore neonatal hyperphenylalaninaemia has been reported to be higher in patients who were $\mathrm{CRM}^{+}$than in patients who were $\mathrm{CRM}^{-}$. ${ }^{9}$

Within the DHPR deficiency the relative frequency of non-responding and responding cases to the oral load of $\mathrm{BH}_{4}$ has been reported in worldwide surveys as $1: 3-1: 4,{ }^{4}{ }^{14}$ although this may not be true for the Italian population, as two out of four patients, both originally from Sicily, did not respond to the load. ${ }^{2}$ A continuum of conditions is to be expected, depending on differences in the mutations. Cases with residual reductase activity ${ }^{18}$ or partial $\mathrm{CRM}^{+9}$ are known to have a milder course.

\section{References}

1 McKusick VA. Mendelian inheritance in man. Baltimore: John Hopkins University Press, 1983.

2 Ponzone A, Ricca V, Ferraris S, et al. DHPR deficiency in Italy. $J$ Pediatr 1984;105:1008.

${ }^{3}$ Firgaira FA, Choo KH. Cotton RGH, Danks DM. Heterogeneity in the molecular defect in human dihydropteridine reductase deficiency. Biochem J 1981:198:677-82.

+ Niederwieser A, Ponzone A, Curtius HCh. Differential diagnosis of tetrahydrobiopterin deficiency. J Inher Metab Dis 1985;8 (suppl 1):34-8.

Ponzone A. Guardamagna O, Ferraris S. Biasetti S, Bracco G. Niederwieser A. Neurotransmitter therapy and diet in malignant phenylketonuria. Eur J Pediatr 1987;146:93-4.

- Arai N, Narisawa K. Hayakawa M, Tada K. Hyperphenylalaninemia due to dihydropteridine reductase deficiency: diagnosis by enzyme assay on dried blood spots. Pediatrics 1982;70: 426-30.

${ }^{7}$ Firgaira FA, Cotton RGH, Danks DM. Human dihydropteridine reductase. A method for the measurement of activity in cultured cells and its application to malignant hyperphenylalaninemia. Clin Chim Acta 1979;197:47-59.

${ }^{x}$ Firgaira FA, Choo KH, Cotton RGH, Danks DM. Molecular and immunological comparison of human dihydropteridine reductase in liver, cultured fibroblasts and continuous lymphoid cells. Biochem J 1981;197:45-53.

" Cotton RGH, Jennings I, Bracco G, Ponzone A, Guardamagna $O$. Tetrahydrobiopterin non-responsiveness in dihydropteridine reductase deficiency is associated with the presence of mutant protein. J Inher Metab Dis 1986:9:239-43.

10 Laemmli UK. Cleavage of structured proteins during the assembly of the head of bacteriophage T4. Nature 197();227:680-5.

" Niederwieser A, Curtius HCh, Wang M, Leupold D. Atypical phenylketonuria with defective biopterin metabolism. Monotherapy with tetrahydrobiopterin or sepiapterin, screening and study of biosynthesis in man. Eur J Pediatr 1982;138:110-2.

12 Niederwieser A, Staudenmann W, Wetzel E. High performance liquid chromatography with column switching for the analysis of biogenic amine metabolites and pterins. J Chromatogr 1984;290: 237-46.

13 Güttler F, Hansen G. Different phenotypes for phenylalanine hydroxylase deficiency. Ann Clin Biochem 1977;14:124-34.

14 Dhondt JL. Tetrahydrobiopterin deficiencies: Preliminary analysis from an international survey.J Pediatr 1984;104:501-8.

15 Firgaira FA, Cotton RGH, Danks DM. Human dihydropteridine reductase deficiency. Demonstration of DHPR ${ }^{-}$CRM and DHPR ${ }^{-} \mathrm{CRM}^{+}$mutants. In: Blair JA, ed. Chemistry and biology of pteridines. Berlin: Walter de Gruyter and Co, 1983:771.

${ }^{16}$ Lipson A, Yu J, O'Halloran M, Potter M, Wilken B. Dihydropteridine reductase deficiency: non-response to oral tetrahydrobiopterin load test. J Inher Metab Dis 1984;7:69-71.

17 Ponzone A, Guardamagna O, Ferraris S, Bracco G, Cotton RGH. Screening for malignant phenylketonuria. Lancet 1987;i: 512-3.

18 Nakabayashi H, Owada M, Kitigawa T. A mild case of dihydropteridine reductase deficiency with residual activity in crythrocytes. J Inher Metab Dis 1984;7:135-6.

Correspondence and requests for reprints to $\mathrm{Dr}$ A Ponzone. Clinica Pediatrica dell'Universitá, Piazza Polonia, 94, 10126 Torino, Italy.

Received 25 September 1987 